Diagnosis and Management of Medical Emergencies (2nd edition)

By Rustom Jal Vakil and Farokh ERach Udwadia. Pp. xx +750 , illustrated, hard cover. Oxford University Press: 1975 (Reprint 1976). $£ 10.00$.

This is a remarkable book in many ways. In the first place it is encyclopaedic and its title belies the fact that there are chapters on paediatrics, ophthalmology, ENT and gynaecological emergencies. Secondly, its real strength lies in the feeling with which it is written, which breathes the life of the casualty department and bedside into the text. As a textbook in differential diagnosis which must, of course, precede optimum management, the book is first-rate.

The book is written by a number of authors mainly from the Bombay hospitals. The Indian setting is reflected in the strange (to British eyes) trade names of some drugs, and the space given to important tropical diseases and now largely extinct European ones. These sections could none the less be of considerable value even if the British accident and emergency doctor does not need to know the details that identify the king cobra.

Inevitably one can quibble with many details of the treatment advised-attempts at early ambulation in myocardial infarction are not recommended, whereas vasopressors and anticoagulants are. The newest techniques in treating diabetic ketosis are not mentioned although it should be noted that the book was published in 1975, the review copy having been somewhat detailed. The index is also not one of the strong points nor is the print, by British standards. With certain caveats, Doctors Vakil and Udwadia's book can certainly be warmly recommended.

\section{Hematology of Infectious Diseases}

By Julian Aleksandrowicz and Jerzy Lisiewicz Pp. 259, illustrated, hard cover. Polish Medical Publishers: Warsaw, 1976. $\$ 9.00$ (for sale through the National Technical Information Service, U.S. Department of Commerce, 5285 Port Royal Road, Springfield, Virginia 22161, U.S.A).

This is a translation of the third edition of this book dealing with the blood in infectious diseases. The first edition published in Polish appeared in 1951. The early chapters deal with the lymphoreticuiar system, the myeloid system and blood proteins. Enzymes in cells are considered in some detail. Thereafter there is a chapter on the 'metals of life' which include iron and trace elements such as copper and manganese. The major section of the book is concerned with blood changes in infections due to viruses, bacteria, mycoses, protozoa and helminths.

Inevitably there are some relatively minor differences in nomenclature. There is a large bibliography and many of the publications are from European authors whose writing may not be well known in the West.

Perhaps one wishes that the comments were more critical with less tendency to bundle together variegated comments on blood findings from a host of sources and perhaps a greater effort at painting a cohesive picture. On the other hand it is fair to say that there is not likely to be a great deal recorded about blood changes in rabies, dengue fever, Lassa fever, listeriosis, etc., and we should be grateful to the authors for directing our attention to some of the observations recorded in these and a host of other infections. Where else could you confirm that disseminated intravascular coagulation has been recorded in Bolivian and Kyasanur forest fever and that platelet numbers may be decreased in those whose unsocial habits have given them the "clap"?
Influenza: Virus, Vaccines and Strategy

Edited by Philip Selby. Pp. 354, illustrated, soft cover. Academic Press: London, 1976. £9.00, \$19.75.

The working group on pandemic influenza met at Rougemont in January, 1976. This volume documents the proceedings of the meeting which was based on an inter-disciplinary approach, including virology, economics, public health administration and epidemiology. The current situation is reported and discussed from all these points of view with the emphasis on surveillance and prevention of the disease.

Just after the meeting the outbreak of swine influenza at Fort Dix became known, and the epilogue of the book is entitled 'Swine influenza: the start of a new pandemic?'. This proved not to be so, but there is no doubt that as years go by one is conscious of the fact that the virus is remaining ominously quiet.

It is interesting and reassuring to learn of developments in the vaccine field, both from the point of view of accelerated production and also of the interest in live vaccines and subunit preparations. The trials of amantidine are encouraging and indicate that the drug may prove a useful adjunct to vaccination in the face of a new pandemic.

There is a good deal of information which will be of nterest to the clinical microbiologist and to workers in the other disciplines mentioned.

It is a sign of the times that a paperback without plates is offered at this price, but this would appear to be reasonable value for money.

\section{Introduction to Physiology. Volume 3}

By Hugh Davson and M. B. Segal. Pp. $x+656$, illustrated hard cover. Academic Press: London, 1976. £9.80.

The authors of this series are planning to introduce the reader to physiology in six volumes.

Volumes 1 and 2 came out in 1975 and provided the reader with a substantial foundation of the basic physical and chemical mechanisms in physiology. This third volume is the first of two to deal with control mechanisms. The fields covered in the present volume are indicated by the main chapter titles; the control of body temperature, the control of the vascular circulation, control of respiration, control mechanisms in the alimentary process, homeostasis of the blood composition and homeostasis in the nervous system. Each chapter is divided into a number of useful subheadings. The present state of knowledge is explained by brief allusion to the experimental evidence. The latter is frequently illustrated by clear figures which are mostly taken from original papers. References from the text and illustrations are listed with the full titles at the end of each chapter. The subject index gives pagination only to the present volume. While there are a few cross references to previous volumes in the text, it is generally assumed that the reader is already familiar with the material of the preceding volumes.

The material is presented in a highly readable and sometimes provocative manner. Medical students with access to the series will enjoy exploring the subject in somewhat greater depth than is possible in the standard textbook, while B.Sc. Honours students will find it an excellent background to their reading of the literature. Many teachers will welcome the series as a valuable basis for their lectures.

\section{An Introduction to Primary Medical Care}

By D. C. Morrell. Pp. ix +138 , soft cover. Churchill Livingstone: Edinburgh. 1976. £1.95.

In 1965 , shortly after he first went into general practice, David Morrell was plainly told by his senior colleagues that 